\title{
Using Biologics in Inflammatory Arthritis: Assessing the Risks and Benefits
}

\author{
Gina Rohekar MD FRCPC MSc (Clin Epi)
}

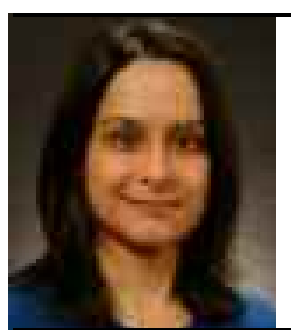

About the Author

Gina Rohekar is an assistant professor at Western University. She also works at St. Joseph's Health Care, in London, Ontario. Her research interest is early rheumatoid arthritis. Correspondence may be directed to Gina.Rohekar@sjhc.london.on.ca.

I nflammatory arthritis, such as rheumatoid arthritis (RA), is not simply a disease that affects an individual with symptoms in the present. It also has tremendous impact on the patient's future well-being. RA has been proposed to be an interrelated triad of disease activity, joint damage, and disability. ${ }^{1}$ In this triad, current disease activity (pain, swelling, and stiffness of joints) leads to disability and decreased quality of life. Furthermore, disease activity leads to joint damage, which also leads to disability. ${ }^{1}$ In the modern treatment of inflammatory arthritis, the goal is to not only treat the present symptoms (disease activity) but also, by doing so, to decrease damage and disability and improve quality of life. There is a movement to treat inflammatory arthritis aggressively and early, with the thought that there is a "window of opportunity" in which early intervention can prevent long-term consequences.

When traditional disease-modifying anti-rheumatic drugs (DMARDs) cannot control inflammation in inflammatory arthritis, the treating physician must decide whether or not the patient's condition requires treatment with biologic medication. This decision is sometimes difficult to make, especially if the treating physician feels uncomfortable in judging the risks and benefits of biologics. In some cases, the decision to start biologics is clear - such as in patients with many swollen joints, erosive disease, and worsening damage. However, in milder or moderate cases, the treating physician is left to judge whether the benefits of biologics outweigh their risks. In this article, I explore the risks and benefits of using biologics to control inflammatory arthritis from an evidencebased perspective.

\section{Benefits of Biologics}

The first and foremost question with regard to biologic use is whether or not they are efficacious - in symptom control, in radiographic inhibition of damage, and in prevention of disability. The efficacy of the biologic agents in symptom control has been shown in many articles. Since it is beyond the scope of this article to comprehensively review every biologic trial, instead I highlight a few examples that I feel are illustrative.

\section{Do Biologics Control Symptoms and Improve Function?}

Numerous studies have shown that biologic agents are efficacious to control the signs and symptoms of RA. As mentioned previously, the efficacy of biologics to treat the symptoms of inflammatory arthritis has been well established. A 2009 Cochrane overview defined benefit as a 50\% improvement in the American College of Rheumatology symptomatic criteria (ACR50). ${ }^{2}$ This means a $50 \%$ improvement in swollen joint and tender joint counts, and a $50 \%$ improvement in at least three of patient global assessment, physician global assessment, pain score, physical function (Health Assessment Questionnaire [HAQ] score), and laboratory acute phase reactants (erythrocyte sedimentation rate $[\mathrm{ESR}]$ or C-reactive protein $[\mathrm{CRP}]) .{ }^{2}$ Compared with the use of placebo, the use of biologics was associated with a significantly higher likelihood of achieving an ACR50 response (odds ratio of 3.35, 95\% confidence interval [CI] 2.62-4.29). ${ }^{1}$ When looking at individual biologics, adalimumab, abatacept, anakinra, etanercept, infliximab, and rituximab were included. ${ }^{2}$ With the exception of anakinra, each biologic studied was associated with a significantly greater chance than placebo of achieving an ACR50. ${ }^{2}$

\section{Do Biologics Prevent Radiographic Progression and Damage?}

The prevention of radiographic damage is the key to reducing disability and improving quality of life in inflammatory arthritis. ${ }^{1}$ A number of studies have shown that biologics (anti- 
tumour necrosis factor [TNF] drugs, in particular) slow radiographic damage in RA. Importantly, this retardation of joint destruction may occur even when patients do not have significant levels of symptom relief. For example, patients who received both methotrexate (MTX) and infliximab in the ATTRACT study demonstrated a reduction in total sharp scores (TSS, a measure of radiographic damage), despite a lack of improvement in clinical measures such as swollen joint count and HAQ scores. ${ }^{3}$ Similarly, the PREMIER study ${ }^{4}$ compared patients who were taking a combination of MTX and adalimumab versus those on either drug alone as monotherapy. Radiographic progression of patients in the MTX-only group was greater than that of patients in the two other groups. ${ }^{4}$ There have even been some studies that lend credence to the theory that biologics may repair structural damage. When etanercept and MTX were initiated in early RA, the TSS on radiographs done at 52 weeks showed a negative TSS change of 0.5 units, implying that there was less radiographic damage seen on these radiographs than on those taken at the start of the study. ${ }^{5}$ These results must of course be interpreted with the caveat that the minimal clinically important change in TSS is considered to be $5{ }^{6}$ Even considering this, negative changes in TSS have also been shown to significantly correlate with lower HAQ scores (in the case of treatment with etanercept in the TEMPO trial), ${ }^{7}$ and this lends support to the theory that even small amounts of radiographic change may be meaningful.

\section{Do Biologics Reduce Disability?}

While biologics are well established to be effective in treating symptoms and preventing damage, it is important to also examine whether they are effective in preventing disability. Inflammatory arthritis typically affects adults in their prime working years. Economically, the cost of disability and lost productivity from this is considerable. A 2006 Canadian study found the annual indirect cost of arthritis was $\$ 11,533$ per person. ${ }^{8}$ These costs were attributable to not only lost work (absenteeism) but also reduced work performance (presenteeism), job changes, and job loss. Additionally, work disability due to arthritis can lead to changes in employment. Patients who experience more arthritis-related work transitions have been shown to have more depressive symptoms ${ }^{9}$ and less ability to care for their arthritis. ${ }^{10}$

Studies looking at the effect of treatment of RA with biologics have shown somewhat-conflicting results. While some have shown lower rates of work disability in the "biologic era" (post-2000), others have not shown significant differences. For example, a Swedish group has recently examined the impact of biologic therapy on the incidence of permanent work disability in RA before and after the introduction of biologics ${ }^{11}$; it showed a reduction in the incidence of disability pensions due to RA in later years that coincides with the introduction of biologics. ${ }^{11}$

Work outcomes with treatment of biologic agents have also been studied in ankylosing spondylitis (AS). The ASSERT trial was a multi-centre, double-blind, placebo-controlled randomized trial of infliximab in $\mathrm{AS}^{12}$ that collected patient-reported workrelated outcomes as well as a structured questionnaire of work data. ${ }^{13}$ This trial showed that patients treated with infliximab for 24 weeks had improvements in work productivity and lost fewer work days than those in the placebo group. ${ }^{13}$ Similar results have been shown with adalimumab ${ }^{14}$ and etanercept. ${ }^{15}$ Psoriatic arthritis trials have also shown an increase in productivity with treatment with biologics. ${ }^{16-18}$

\section{Risks of Biologics}

Clearly, biologic medications are efficacious in not only treating the clinical symptoms of RA but also reducing radiographic damage and disability. However, the biologics are not without their risks. These must be considered in each individual patient before treatment with biologics is initiated.

\section{What Is the Overall Risk of Adverse Events and Withdrawals Due to Adverse Events?}

A Cochrane review ${ }^{19}$ of 163 trials with over 50,000 patients found that overall, when compared with placebo, biologics were associated with a higher rate of adverse events, withdrawals due to adverse events, and tuberculosis (TB) reactivation. ${ }^{19}$ The number needed to harm was 37 (95\% CI 19-190). ${ }^{19}$ Overall, biologic use was associated with a $3 \%$ higher rate of withdrawals due to adverse events. ${ }^{19}$

\section{What Is the Risk of Infection?}

An increased risk of bacterial infections has been seen in patients treated with biologic medications versus those treated with traditional DMARDs, especially in cases of pneumonia and skin infections. ${ }^{20}$ The risk of infection was highest within the first 6 months of starting biologic drugs. ${ }^{20}$ The risk increased with higher disability (HAQ), older age of the patient, co-morbidities, and past hospitalizations. ${ }^{20}$ To put this into perspective, however, we can consider the adverse effects of steroids in treating RA - researchers have found a greater risk of hospitalization with pneumonia for those patients with RA using prednisone than in those using TNF inhibitors and MTX. $^{21}$

An increased rate of $\mathrm{TB}$ reactivation with the use of biologics has been well established. ${ }^{22,23}$ The Canadian Rheumatology Association's 2012 recommendations for the 
pharmacological management of RA urged screening for latent TB prior to treatment with anti-TNF agents, abatacept, and tocilizumab. $^{24}$

As well, screening for hepatitis B and C and, in high-risk patients, human immunodeficiency virus (HIV) is recommended prior to starting any biologic therapy. ${ }^{24}$ According to the American College of Rheumatology 2012 update of the recommendations for the treatment of RA, no biologic should be used in cases where patients have untreated chronic hepatitis B or treated hepatitis B with Child-Pugh class $\mathrm{B}$ or higher. ${ }^{25}$ No recommendation was able to be made for patients with a history of hepatitis B and a positive hepatitis B core antibody. ${ }^{25}$ In cases of hepatitis $\mathrm{C}$, etanercept was the suggested biologic of choice. ${ }^{25}$

\section{What Is the Risk of Malignancy?}

Overall, studies looking at potential increased malignancy risk with biologic use have been reassuring. Because long-term data are required for proper assessment of malignancy risk, registries have been particularly useful. The British Society for Rheumatology Biologics Register has shown no increased mortality from cancer and has reported a relative risk of cancer death of 0.65 (95\% CI 0.39-1.09). ${ }^{26}$ Similar findings have been shown in studies of cancer incidence in Germany (the German biologics register RABBIT) and Sweden (ARTIS). ${ }^{27,28}$

Risk of lymphoma has historically been a concern with biologic use. With regards to lymphomas, the 2012 Cochrane review of adverse effects found no increase in the rate of lymphoma when biologic use was compared to placebo, ${ }^{19}$ though it should be noted that the overall lymphoma rates were low. Data from ARTIS showed no increased relative risk of lymphoma when comparing patients with RA who used TNF inhibitors to those who were not exposed to biologics. ${ }^{29}$ Other registry data have been similarly reassuring. ${ }^{30}$

In contrast to lymphoma and other solid tumors, there does appear to be an increase in the risk of skin cancers with TNF inhibitor use, ${ }^{30}$ both with regard to squamous cell skin cancer and malignant melanoma. ARTIS showed a relative risk of 1.5-2 for both squamous cell and melanoma, ${ }^{30}$ and, similarly, a US databank showed an overall risk of non-melanoma squamous cell skin cancer to be 1.5 (95\% CI 1.2-1.8) and melanoma to be 2.3 (95\% CI 0.9-5.4). ${ }^{31}$

\section{What Is the Risk of Congestive Heart Failure?}

The 2012 Cochrane review found no increased risk of congestive heart failure (CHF) with biologics as compared with control treatments. ${ }^{19}$ Despite this, the 2012 recommendations from the ACR state that anti-TNFs should not be used in patients with CHF that is New York Heart Association (NYHA) class III or IV, or those who have an ejection fraction of $50 \%$ or less. ${ }^{25}$ The level of evidence for this recommendation was $\mathrm{C}$.

\section{What Is the Risk of Neurologic Disease?}

Multiple studies have shown that TNF- $\alpha$ inhibitors may be implicated in the development of inflammatory demyelinating central nervous system (CNS) diseases such as multiple sclerosis (MS) and optic neuritis. ${ }^{32}$ This is actually a surprising finding since TNF excess can be seen with MS. ${ }^{32}$ As of July 2009, there have been over 140 cases reported of demyelinating CNS diseases after starting biologic therapies. ${ }^{32}$ Importantly, it should be noted that stopping the anti-TNF agent does not always lead to a resolution of the demyelination..$^{32}$ In the case of rituximab, progressive multifocal leukoencephalopathy has been reported. ${ }^{32}$

\section{Are Biologics Cost-Effective?}

Since biologics are very expensive, some consideration should be given to their cost-effectiveness. Barra et al. looked at the cost-effectiveness of anti-TNF drugs in a real-world, outpatient setting. ${ }^{33}$ They took into consideration the high price tag (about $\$ 20,000 /$ year) as well as the need for ongoing, long-term use of these drugs. To determine cost-effectiveness, they looked at the cost per year of achieving a minimally clinically important difference in HAQ scores, and considered direct drug costs only. ${ }^{33}$ With a number needed to treat of 1.50 to 2.34 , the calculated costs ranged from $\$ 31,866$ to $\$ 50,752$ per year. ${ }^{33}$ Whether this value can be considered cost-effective must be evaluated in the context of the impact of preventing radiographic damage and work disability.

A 2011 systematic review of current literature looked at 18 cost-effective analyses ${ }^{34}$ and found that biologics were not costeffective, using the threshold of $\$ 50,000$ per quality adjusted life year (QALY) gained, for patients who had failed MTX combination therapy or sequential DMARDs. ${ }^{34}$ The review suggested that the most cost-effective use of biologics was to use traditional DMARDs early in the disease and to add biologics if there was not a response to traditional medications. $^{34}$

\section{Assessing Patients for Risk with Biologics}

Assessing an individual patient's risk of harm from treatment with biologics can be challenging and must be weighed against that patient's risk of harm due to the underlying inflammatory arthritis. For treating physicians, a useful resource to help assess the risks of treatment with biologics can be found at www.rheuminfo.com, which has a Biologics Safety Screening 
Tool that can be used in individual assessments. This tool can also be used to document reviewing the risks of biologics with a patient before they are initiated. The form is downloadable from http://rheuminfo.com/physician-tools/biologics-screening-tool.

Biologic medications have certainly revolutionized the treatment of inflammatory arthritis but are often looked at by practitioners and patients with trepidation. When weighing the risks and benefits, it is important to discuss not only the risks of treatment but also the risks of not treating inflammatory arthritis (irreversible damage). We are fortunate to be able to prevent such damage in the modern era of treating inflammatory arthritis, whether it is through the use of biologics or by simply treating active inflammation aggressively with less expensive standard DMARDs.

\section{References}

1. Keystone EC, Smolen J, van Riel P. Developing an effective treatment algorithm for rheumatoid arthritis. Rheumatology (Oxford) 2012;51 Suppl 5:v48-54.

2. Singh JA, Christensen R, Wells GA, et al. A network meta-analysis of randomized controlled trials of biologics for rheumatoid arthritis: a Cochrane overview. CMAJ 2009;181(11):787-96.

3. Smolen JS, Han C, Bala M, et al.; ATTRACT Study Group. Evidence of radiographic benefit of treatment with infliximab plus methotrexate in rheumatoid arthritis patients who had no clinical improvement: a detailed subanalysis of data from the anti-tumor necrosis factor trial in rheumatoid arthritis with concomitant therapy study. Arthritis Rheum 2005;52(4):1020-30.

4. Emery P, Genovese MC, van Vollenhoven R, et al. Less radiographic progression with adalimumab plus methotrexate versus methotrexate monotherapy across the spectrum of clinical response in early rheumatoid arthritis. J Rheumatol 2009;36(7):1429-41.

5. van der Heijde D, Landewé R. Imaging: do erosions heal? Ann Rheum Dis 2003;62 Suppl 2:ii10-2.

6. Bruynesteyn K, van der Heijde D, Boers M, et al. Minimal clinically important difference in radiological progression of joint damage over 1 year in rheumatoid arthritis: preliminary results of a validation study with clinical experts. J Rheumatol 2001;28(4):904-10.

7. van der Heijde D, Landewé R, van Vollenhoven R, et al. Level of radiographic damage and radiographic progression are determinants of physical function: a longitudinal analysis of the TEMPO trial. Ann Rheum Dis 2008;67(9):1267-70.

8. Li X, Gignac MA, Anis AH. The indirect costs of arthritis resulting from unemployment, reduced performance, and occupational changes while at work. Med Care 2006;44(4):304-10.

9. Gignac MA, Badley EM, Lacaille D, et al. Managing arthritis and employment: making arthritis-related work changes as a means of adaptation. Arthritis Rheum 2004;51(6):909-16.

10. Gignac MA, Sutton D, Badley EM. Reexamining the arthritis-employment interface: perceptions of arthritis-work spillover among employed adults. Arthritis Rheum 2006;55(2):233-40.

11. Hallert E, Husberg M, Bernfort L. The incidence of permanent work disability in patients with rheumatoid arthritis in Sweden 1990-2010: before and after introduction of biologic agents. Rheumatology (Oxford) 2011;51(2):338-46.

12. Puolakka K, Kautiainen H, Mottonen T, et al. Early suppression of disease activity is essential for maintenance of work capacity in patients with recent-onset rheumatoid arthritis: five-year experience from the FIN-RACo trial. Arthritis Rheum 2005;52(1):36-41.

13. van der Heijde D, Han C, DeVlam K, et al. Infliximab improves productivity and reduces workday loss in patients with ankylosing spondylitis: results from a randomized, placebo-controlled trial. Arthritis Rheum 2006;55(4):569-74.

14. Maksymowych WP, Gooch KL, Wong RL, et al. Impact of age, sex, physical function, health-related quality of life, and treatment with adalimumab on work status and work productivity of patients with ankylosing spondylitis. J Rheumatol 2010;37(2):385-92.

15. Barkham N, Coates LC, Keen H, et al. Double-blind placebo-controlled trial of etanercept in the prevention of work disability in ankylosing spondylitis. Ann Rheum Dis 2010;69(11):1926-8.

16. Kavanaugh A, Antoni C, Mease P, et al. Effect of infliximab therapy on employment, time lost from work, and productivity in patients with psoriatic arthritis. J Rheumatol 2006;33(11):2254-9.

17. Gladman DD, Psaradellis F, Martel MJ. Impact of adalimumab (Humira) on work productivity in patients with psoriatic arthritis: results from ACCLAIM. CRA meeting. J Rheumatol 2009;6 Suppl 2:2595.

18. Gladman DD, Bombardier C, Thorne C, et al. Effectiveness and safety of etanercept in patients with psoriatic arthritis in a Canadian clinical practice setting: the REPArE trial. J Rheumatol 2011;38(7):1355-62.

19. Singh JA, Wells GA, Christensen R, et al. Adverse effects of biologics: a network meta-analysis and Cochrane overview. Cochrane Database Syst Rev 2011;(2):CD008794.

20. Nam JL, Winthrop KL, van Vollenhoven RF, et al. Current evidence for the management of rheumatoid arthritis with biological disease-modifying antirheumatic drugs: a systematic literature review informing the EULAR recommendations for the management of RA. Ann Rheum Dis 2010;69(6):976-86

21. Wolfe F, Caplan L, Michaud K. Treatment for rheumatoid arthritis and the risk of hospitalization for pneumonia: associations with prednisone, disease-modifying antirheumatic drugs, and anti-tumor necrosis factor therapy. Arthritis Rheum 2006;54(2):628-34.

22. Dixon WG, Watson K, Lunt M, et al.; British Society for Rheumatology Biologics Register. Rates of serious infection, including site-specific and bacterial intracellular infection, in rheumatoid arthritis patients receiving anti-tumor necrosis factor therapy: results from the British Society for Rheumatology Biologics Register. Arthritis Rheum 2006;54(8):2368-76.

23. Askling J, Fored CM, Brandt L, et al. Risk and case characteristics of tuberculosis in rheumatoid arthritis associated with tumor necrosis factor antagonists in Sweden. Arthritis Rheum 2005;52(7):1986-92.

24. Bykerk VP, Akhavan P, Hazlewood GS, et al. Canadian Rheumatology Association recommendations for pharmacological management of rheumatoid arthritis with traditional and biologic disease-modifying antirheumatic drugs. J Rheumatol 2012;39(8):1559-82.

25. Singh JA, Furst DE, Bharat A, et al. 2012 update of the 2008 American College of Rheumatology recommendations for the use of diseasemodifying antirheumatic drugs and biologic agents in the treatment of rheumatoid arthritis. Arthritis Care Res (Hoboken) 2012;64(5):625-39.

26. Lunt M, Watson KD, Dixon WG, et al.; British Society for Rheumatology Biologics Register. No evidence of association between anti-tumor necrosis factor treatment and mortality in patients with rheumatoid arthritis: results from the British Society for Rheumatology Biologics Register. Arthritis Rheum 2010;62(11):3145-53.

27. Strangfeld A, Hierse F, Rau R, et al. Risk of incident or recurrent malignancies among patients with rheumatoid arthritis exposed to biologic therapy in the German biologics register RABBIT. Arthritis Res Ther 2010;12(1):R5.

28. Askling J, van Vollenhoven RF, Granath F, et al. Cancer risk in patients with rheumatoid arthritis treated with anti-tumor necrosis factor alpha therapies: does the risk change with the time since start of treatment? Arthritis Rheum 2009;60(11):3180-9.

29. Askling J, Baecklund E, Granath F, et al. Anti-tumour necrosis factor 


\section{Using Biologics in Inflammatory Arthritis}

therapy in rheumatoid arthritis and risk of malignant lymphomas: relative risks and time trends in the Swedish Biologics Register. Ann Rheum Dis 2009;68(5):648-53.

30. Askling J. The risk of malignancies in RA patients treated with biologics. Z Rheumatol 2010;69(9):774-9.

31. Wolfe F, Michaud K. Biologic treatment of rheumatoid arthritis and the risk of malignancy: analyses from a large US observational study. Arthritis Rheum 2007;56(9):2886-95.

32. Bosch X, Saiz A, Ramos-Casals M; BIOGEAS Study Group. Monoclonal antibody therapy-associated neurological disorders. Nat Rev Neurol 2011;7(3):165-72.
33. Barra L, Pope JE, Payne M. Real-world anti-tumor necrosis factor treatment in rheumatoid arthritis, psoriatic arthritis, and ankylosing spondylitis: cost-effectiveness based on number needed to treat to improve health assessment questionnaire. J Rheumatol 2009;36(7):1421-8.

34. van der Velde G, Pham B, Machado M, et al. Cost-effectiveness of biologic response modifiers compared to disease-modifying antirheumatic drugs for rheumatoid arthritis: a systematic review. Arthritis Care Res (Hoboken) 2011;63(1):65-78. 